\title{
Inverted solar cell with thermally evaporated Selenium as an active layer
}

Wenbo Liu ${ }^{*}$, Ahmed Ali Said †, W. J. Fan ${ }^{*}$, Qichun Zhang ${ }^{*}{ }^{* \#}$

$\dagger$ School of Materials Science and Engineering, Nanyang Technological University, 50 Nanyang Avenue, Singapore 639798. Email: qczhang@ntu.edu.sg

$¥$ School of Electrical and Electronic Engineering, Nanyang Technological University, 50 Nanyang Avenue, Singapore 639798.

\# Department of Materials Science and Engineering, City University of Hong Kong, Kowloon, Hong Kong SAR, China. Email: qiczhang@cityu.edu.hk 
Table S1. Summary of SSCs with organic carrier transport layers.

\begin{tabular}{|c|c|c|}
\hline Publication date ref. & Structure of SSCs & PCE (\%) \\
\hline $2014^{[1]}$ & $\begin{array}{c}\mathrm{FTO} / \text { compact- } \mathrm{TiO}_{2} / \mathrm{mp}-\mathrm{TiO}_{2} / \mathrm{Se} \text { (thermal evaporation)/ } \\
\text { P3HT/PEDOT:PSS/Ag }\end{array}$ & 2.63 \\
\hline $2014^{[1]}$ & $\begin{array}{c}\mathrm{FTO} / \text { compact- } \mathrm{TiO}_{2} / \mathrm{mp}-\mathrm{TiO}_{2} / \mathrm{Se} \text { (thermal evaporation)/ } \\
\text { Spiro-OMeTAD/PEDOT:PSS/Ag }\end{array}$ & 1.83 \\
\hline $2016^{[2]}$ & $\mathrm{FTO} / \mathrm{bl}-\mathrm{TiO}_{2}, \mathrm{mp}^{-\mathrm{TiO}_{2}} / \mathrm{Se}$ (spin-coating)//PTAA$/ \mathrm{Au}$ & 3.55 \\
\hline $2018^{[3]}$ & $\mathrm{FTO} / \mathrm{TiO}_{2} / \mathrm{Se}$ (spin-coating)//Spiro-OMeTAD/Au & 1.23 \\
\hline $2018^{[3]}$ & $\mathrm{FTO} / \mathrm{TiO}_{2} / \mathrm{Se}$ (spin-coating)/P3HT/Au & 1.08 \\
\hline $2018^{[3]}$ & $\mathrm{FTO} / \mathrm{TiO}_{2} / \mathrm{Se}$ (spin-coating)//PTAA/Au & 0.62 \\
\hline This work & ITO/PEDOT:PSS/Se(thermal evaporation)/PCBM/Ag & 3.9 \\
\hline
\end{tabular}



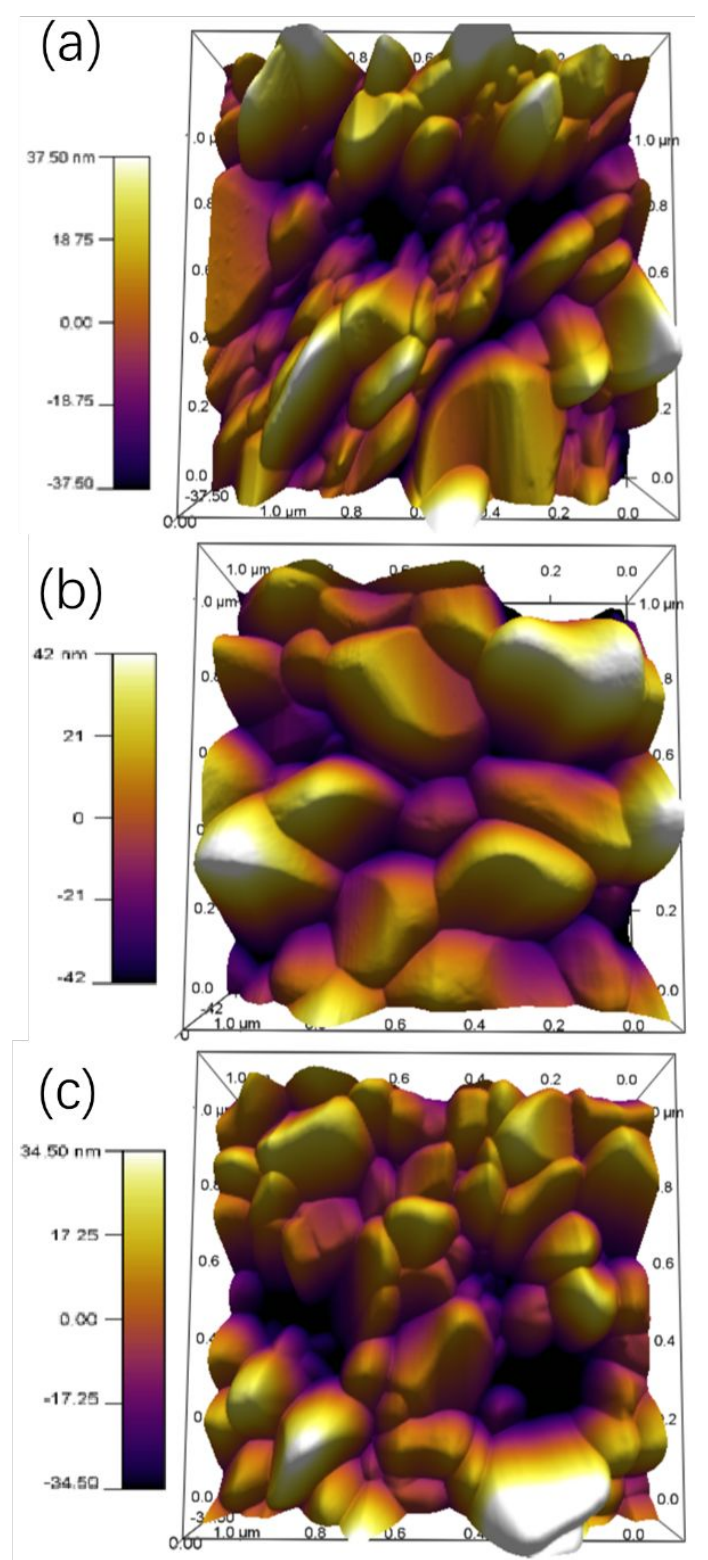

Figure S1. 3D AFM images of Se surface with different growth rate (a) $0.1 \mathrm{~nm} / \mathrm{s}$, (b) $0.3 \mathrm{~nm} / \mathrm{s}$, (c) $0.5 \mathrm{~nm} / \mathrm{s}$. 

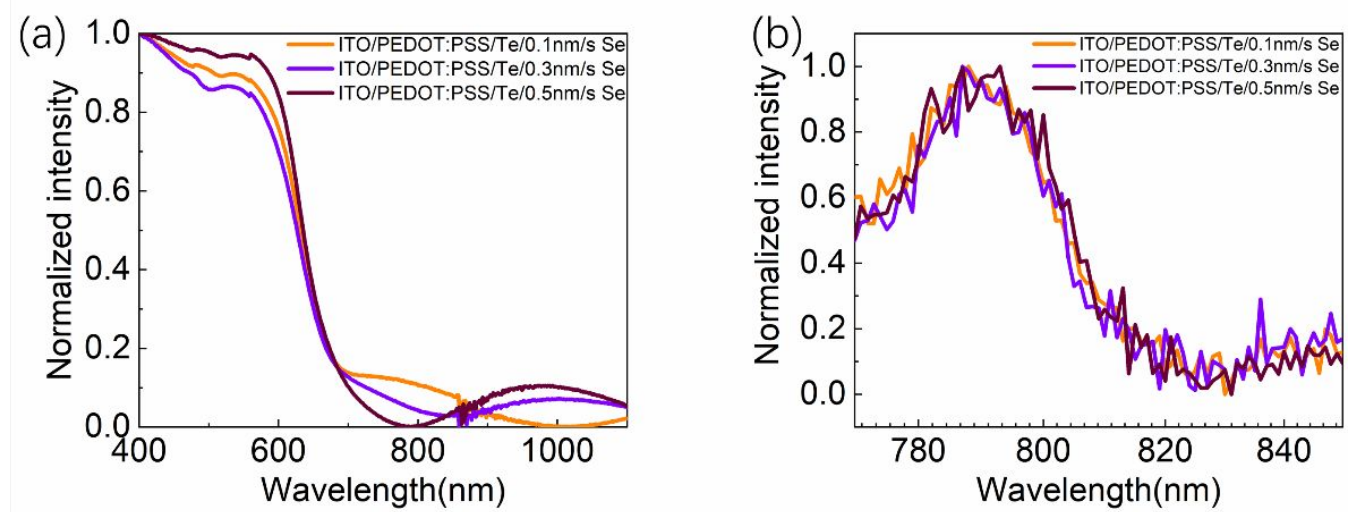

Figure S2. (a) UV-Vis-NIR spectroscopy and (b) PL spectra of Se film with different deposition rates on the ITO/PEDOT:PSS/Te substrate.

\section{Reference:}

(1) Wang, K.; Shi, Y.; Zhang, H.; Xing, Y.; Dong, Q.; Ma T. Selenium as a photoabsorber for inorganic-organic hybrid solar cells. Phys. Chem. Chem. Phys., 2014, 16, 23316-23319.

(2) Zhu, M.; Hao, F.; Ma, L.; Song, T.-B.; Miller, C. E.; Wasielewski, M.R.; Li, X.; Kanatzidis, M. G., Solution-Processed Air-Stable Mesoscopic Selenium Solar Cells. ACS Energy Lett. 2016, 1, 469-473.

(3) Zhu, M.; Deng, Y.; Liu, W.; Li, X. Preparation of Se-based solar cell using spin-coating method in ambient condition. Chin. Phys. B, $2018,27,015202$. 